\title{
Esofagectomia trans-hiatal com esternotomia parcial
}

\section{Transhiatal esophagectomiy using partial sternotomy}

\author{
Alexandre Cruz Henriques, TCBC-SP1; Altair da Silva Costa Junior, ACBC-SP²; Adilson Casemiro Pires33; \\ Carlos Alberto Godinho4; Jaques Waisberg, TCBC-SP5
}

\section{R E S U M O}

\begin{abstract}
A esofagectomia trans-hiatal oferece a vantagem de não necessitar da toracotomia ou toracoscopia. Apresenta a desvantagem de ter que ser realizada, pelo menos em parte, com dissecação romba, às cegas, ocorrendo com frequência lesão pleural, maior sangramento, entre outras complicações. A associação da transecção mediana do diafragma com a esternotomia parcial permite o isolamento do esôfago totalmente sob visão direta. Os autores apresentam a técnica da esofagectomia trans-hiatal com esternotomia parcial.
\end{abstract}

Descritores: Esôfago. Acalasia esofágica. Neoplasias esofágicas. Esofagectomia. Esternotomia.

\section{INTRODUÇÃO}

$V^{2}$ árias vias de acesso foram descritas para a realização da esofagectomia. Podem ser agrupadas, de maneira geral, em duas categorias: via transtorácica e via transhiatal, esta última amplamente difundida por Pinotti ${ }^{1,2} \mathrm{e}$ Orringer et $a l . .^{3,4}$.

Orringer et al.3,4 preconizam o isolamento do esôfago por meio de dissecação romba e às cegas. Pinotti propõe o acesso ao esôfago torácico através da transecção mediana do diafragma ${ }^{2}$ que permite a dissecação do esôfago sob visão direta, principalmente sua porção médio-distal. Esta abordagem torna a técnica da esofagectomia trans-hiatal mais segura e refinada. No entanto, é necessário completar o isolamento do esôfago proximal com dissecação romba por via cervical e por via abdômino-mediastinal, acrescentando morbidade ao procedimento, principalmente lesão pleural, (frequentemente bilateral) e sangramento mais intenso.

Com intenção de realizar o isolamento do esôfago totalmente sob visão direta, pode-se proceder a esternotomia parcial proximal para obter amplo acesso ao mediastino superior. Esta manobra é utilizada para ressecção de tumores do mediastino superior ${ }^{5}$ e do ápice do pulmão em doentes selecionados ${ }^{6}$.

Orringer et al. utilizam a esternotomia parcial em tumores do esôfago proximal ${ }^{7}$ e em doentes cujo biotipo "pescoço curto" tornam o tempo cervical muito trabalho$\mathrm{SO}^{4}$.
O objetivo deste estudo é apresentar a esternotomia parcial em pacientes submetidos à esofagectomia trans-hiatal.

\section{TÉCNICA}

A esofagectomia trans-hiatal é realizada através das vias de acesso abdominal e cervical. Realizamos o tempo abdominal por laparotomia, onde o estômago é preparado e tubulizado, a transecção mediana do diafragma é realizada e o esôfago médio- distal é dissecado sob visão direta.

Realizamos o tempo cervical através de incisão paralela à borda anterior do músculo esternocleidomastoideo, que se prolonga distalmente da fúrcula esternal até pouco abaixo do manúbrio. A esternotomia é realizada em sentido longitudinal, desde a fúrcula até ultrapassar o manúbrio e, a seguir, a secção óssea toma sentido transversal para o lado direito, resultando numa esternotomia com forma da letra $L$ invertido (Figura 1). Um afastador de Finochietto de tamanho apropriado é aplicado de forma a expor amplamente o mediastino superior (Figura 2). O tecido frouxo é dissecado até expor a veia braquio-cefálica esquerda. Com este amplo campo operatório, realizamos o isolamento do esôfago proximal, dissecando-o progressivamente em sentido distal até encontrar o esôfago previamente dissecado por via abdômino-mediastinal, sempre sob visão direta (Figura 3), realizando cuidadosa hemostasia e

Trabalho realizado no Hospital de Ensino da Faculdade de Medicina do ABC- SP-BR

1. Professor Assistente da Disciplina de Cirurgia do Aparelho Digestivo da Faculdade de Medicina do ABC; 2. Professor Assistente da Disciplina de Cirurgia Torácica da Faculdade de Medicina do ABC; 3. Professor Titular da Disciplina de Cirurgia Torácica da Faculdade de Medicina do ABC; 4. Cirurgião do Serviço de Cirurgia do Aparelho Digestivo do Hospital de Ensino da Faculdade de Medicina do ABC; 5 . Professor Regente da Disciplina de Cirurgia do Aparelho Digestivo da Faculdade de Medicina do ABC. 


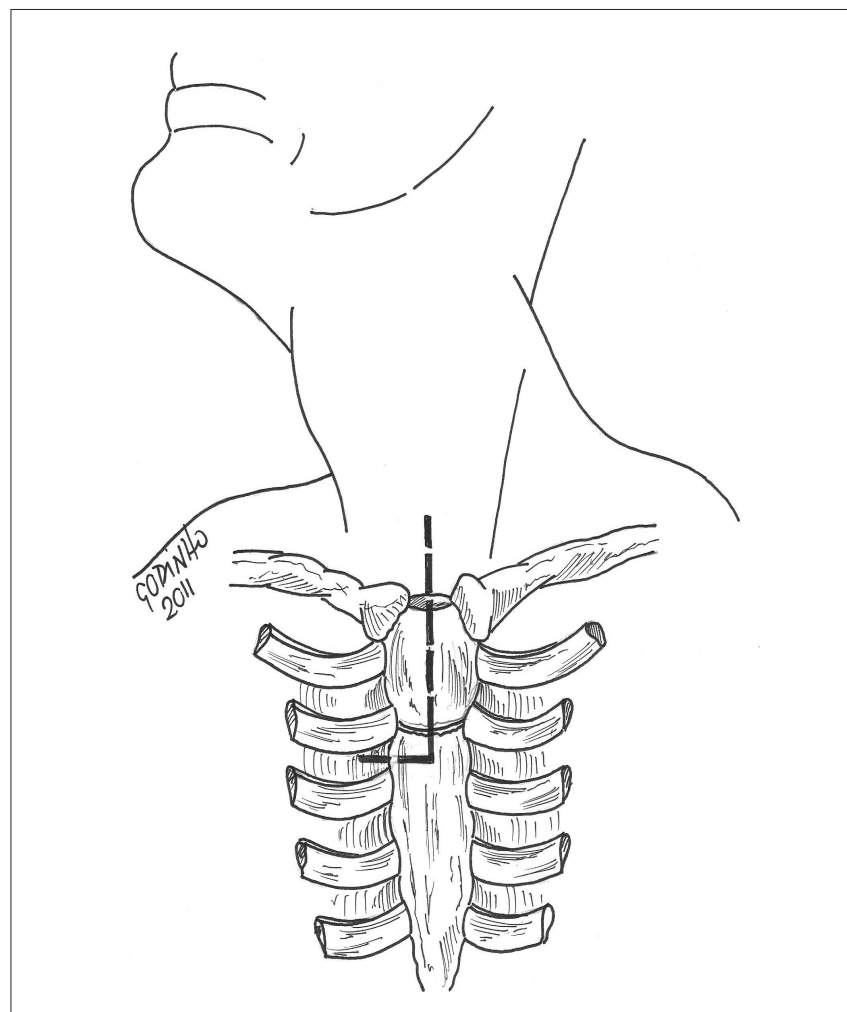

Figura 1 - Esternotomia com a forma da letra "L" invertida.

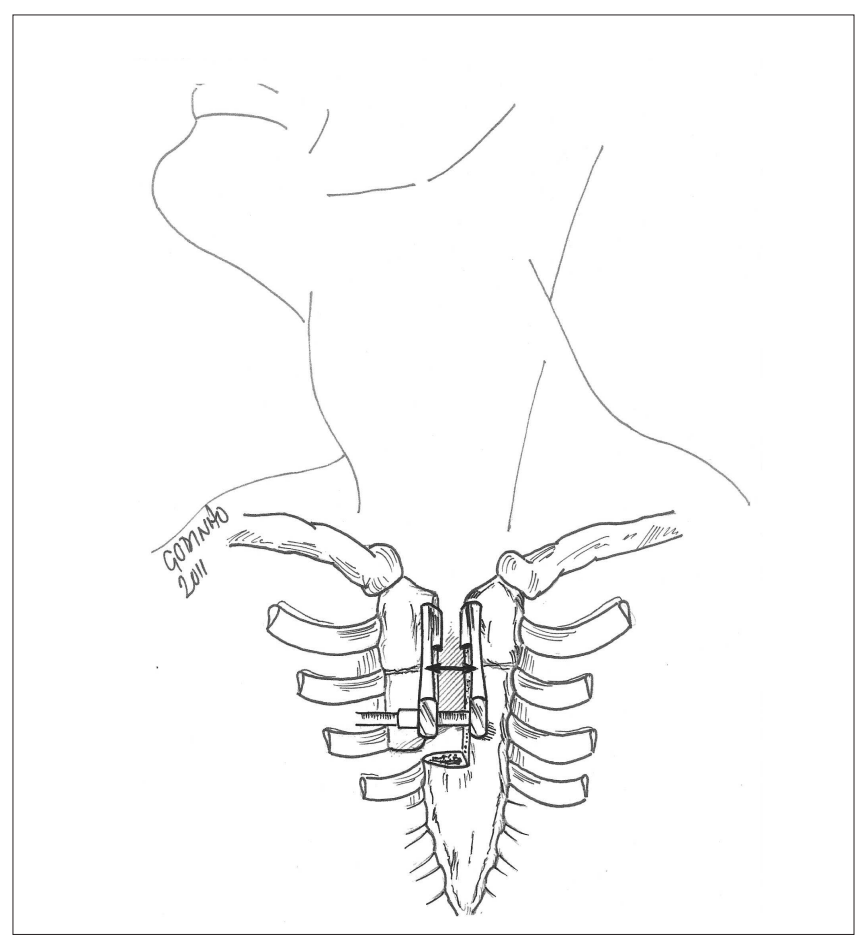

Figura 2 - Colocação do afastador com ampla exposição do campo operatório.

evitando lesão pleural. Após isolamento do esôfago, completamos a esofagectomia e realizamos a transposição do estômago para a região cervical pelo mediastino posterior. A anastomose esofagogástrica é realizada utilizando a técnica de invaginação ${ }^{8,9}$.

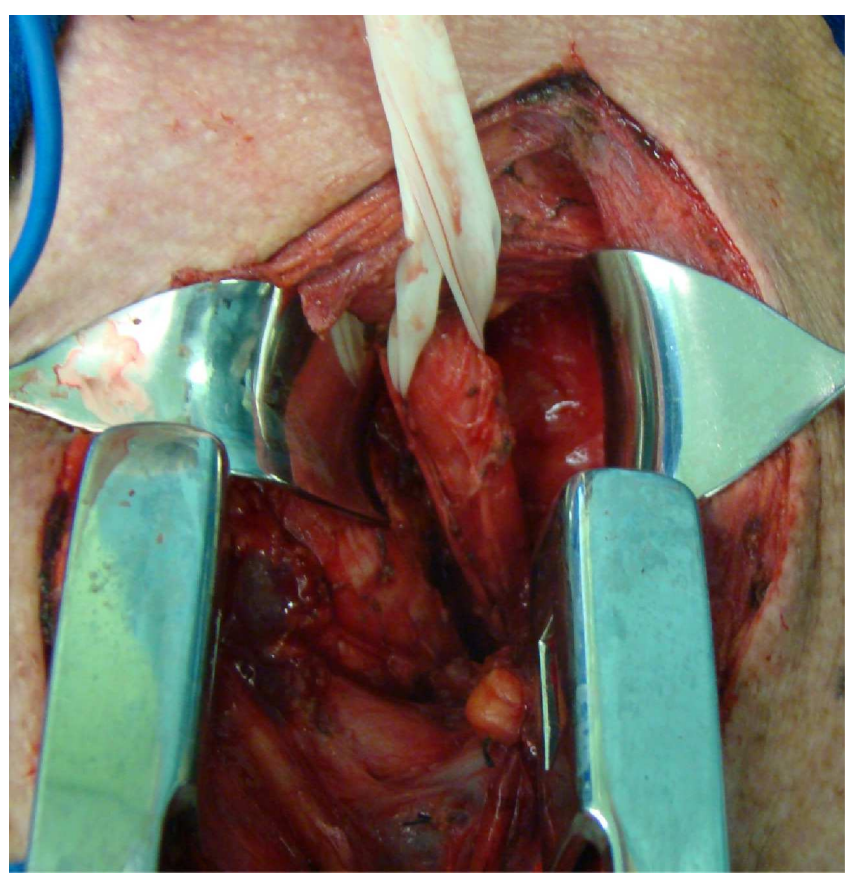

Figura 3 - $\quad$ Aspecto do esôfago proximal amplamente dissecado sob visão direta.

Para diminuir a possibilidade de infecção, durante a indução anestésica a antibióticoprofilaxia é realizada, as bordas ósseas são protegidas com compressas cirúrgicas, o esôfago é seccionado com grampeador linear e a anastomose esofagogástrica é realizada com o cuidado de evitar derramamento do conteúdo gástrico e esofágico no campo operatório.

O esterno é aproximado com fio de aço e a região cervical é drenada com dreno de aspiração a vácuo.

\section{DISCUSSÃO}

A possibilidade de realizar a esofagectomia transhiatal totalmente sob visão direta representa significante melhoria técnica, uma vez que torna a operação mais segura, permite hemostasia cuidadosa e diminui a possibilidade de lesão pleural. A transecção mediana do diafragma permite atingir este objetivo no isolamento do esôfago médio- distal. A esternotomia parcial oferece a possibilidade de completar o isolamento do esôfago totalmente sob visão direta.

A esternotomia parcial não aumenta significantemente o tempo e o trauma operatório e já é utilizada em casos selecionados ${ }^{4,7}$. A esternotomia parcial pode ser associada com a videolaparoscopia, transecção mediana do diafragma e anastomose esofagogástrica com invaginação, e possui o potencial de diminuir a morbimortalidade da esofagectomia.

Todos os cuidados técnicos para minimizar a possibilidade de infecção da ferida operatória devem ser 
utilizados. Julgamos que a anastomose esfagogástrica com a técnica de invaginação ${ }^{8,9}$ diminui a ocorrência de fístula anastomótica e, quando ocorre, apresenta pequena repercussão clínica.
Os resultados preliminares da aplicação deste procedimento mostraram-se promissores, porém a validade desta proposta depende da avaliação dos resultados em número maior de doentes.

\section{A B $S$ S T $T$ R A $A$ C $T$}

Transhiatal Esophagectomy offers the advantage of not requiring thoracotomy or thoracoscopy. Nevertheless, it has the disadvantage of having to be performed, at least in part, with blind, blunt dissection, with high frequency of pleural lesions, increased bleeding, among other complications. The association of median diaphragm transection with partial sternotomy allows the isolation of the esophagus completely under direct vision. The authors present the technique of transhiatal esophagectomy with partial sternotomy.

Key words: Esophagus. Esophageal achalasia. Esophageal neoplasms. Esophagectomy. Sternotomy.

\section{REFERÊNCIAS}

1. Pinotti HW. Acesso extrapleural ao esôfago por frenolaparotomia. Rev Assoc Med Bras. 1976;22(2):57-60.

2. Pinotti HW. Acesso ao esôfago torácico por transecção mediana do diafragma. São Paulo: Atheneu; 1999.

3. Orringer MB, Sloan $\mathrm{H}$. Esophagectomy without thoracotomy. J Thorac Cardiovasc Surg. 1978;76(5):643-54.

4. Orringer MB, Marshall B, Chang AC, Lee J, Pickens A, Lau CL. Two thousand transhiatal esophagectomies: changing trends, lessons learned. Ann Surg. 2007;246(3):363-72; discussion 372-4.

5. Grandjean JG, Lucchi M, Mariani MA. Reserved-T upper ministernotomy for extended thymectomy in myasthenic patients. Ann Thorac Surg. 2000;70(4):1423-4; discussion 1425.

6. Heitmiller RF, Radecke JK, You CJ. Resection of apical lung tumors in high-risk patients using partial sternotomy. Ann Thorac Surg. 2008;85(2):678-80.

7. Orringer MB. Partial median sternotomy: anterior approach to the upper thoracic esophagus. J Thorac Cardiovasc Surg. 1984;87(1):124-9.

8. Henriques AC, Zanon AB, Godinho CA, Martins LC, Saad Júnior R, Speranzini $M B$, et al. Estudo comparativo entre as anastomoses cervicais esofagosgástrica término-terminal com e sem invaginação após esofagectomia para câncer. Rev Col Bras Cir. 2009;36(5):398405.
9. Henriques AC, Godinho CA, Saad R Jr, Waisberg DR, Zanon AB, Speranzini $M B$, et al. Esophagogastric anastomosis with invagination into stomach: New technique to reduce fistula formation. World J Gastroenterol. 2010;16(5):5722-6.

Recebido em 03/08/2011

Aceito para publicação em 06/10/2011

Conflito de interesse: nenhum

Fonte de financiamento: nenhuma

\section{Como citar este artigo:}

Henriques AC, Costa Júnior AS, Pires AC, Godinho CA, Waisberg J. Esofagectomia trans-hiatal com esternotomia parcial. Rev Col Bras Cir. [periódico na Internet] 2012; 39(5). Disponível em URL: http:// www.scielo.br/rcbc

Endereço para correspondência:

Alexandre Cruz Henriques

E-mail: achenriques@uol.com.br 